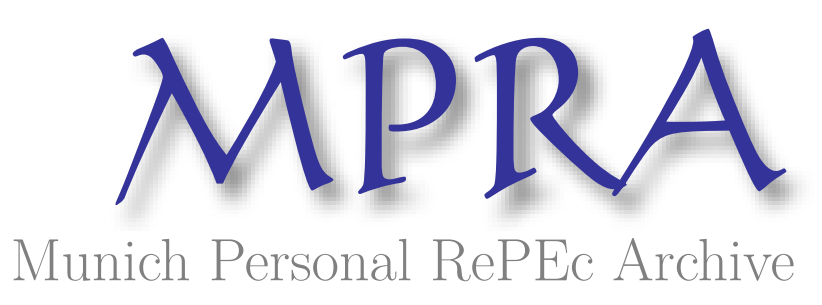

\title{
Tolls, Exchange Rates, and Northbound International Bridge Traffic from Mexico
}

Fullerton, Thomas M., Jr. and Molina, Angel L., Jr. and Walke, Adam G.

University of Texas at El Paso, Texas AM University, University of Texas at El Paso

22 January 2010

Online at https://mpra.ub.uni-muenchen.de/59586/

MPRA Paper No. 59586, posted 01 Nov 2014 09:51 UTC 


\title{
Tolls, Exchange Rates, and Northbound International Bridge Traffic from Mexico
}

JEL Categories: M21, Business Economics; R41, Regional Transportation

Regional Science Policy \& Practice, Volume 5, Number 3, Pages 305-322

Doi: $10.1111 / \mathrm{rsp} 3.12011$

Thomas M. Fullerton, Jr.*, Angel L. Molina, Jr.**, and Adam G. Walke*

* Department of Economics \& Finance, University of Texas at El Paso, El Paso, TX 79968-0543

Telephone 915-747-7747, Facsimile 915-747-6282, Email tomf@utep.edu

** Department of Political Science, Texas A\&M University, College Station, TX 77843-4348

Telephone: 979-845-2511, Facsimile: 979-847-8924, Email angel_1_molina_jr@tamu.edu

\begin{abstract}
Although there have been a small number of empirical studies that analyze northbound border crossings between Mexico and the United States, very few examine the potential impacts of both tolls and exchange rates on the various traffic categories. This effort attempts to partially fill that gap in the applied economics literature by modeling northbound traffic flows at one of the largest regional economies along the border. Results indicate that business cycle fluctuations, variations in the real exchange rate, and changes in real toll tariffs all influence cross border traffic volumes. Tolls on northbound traffic into the United States are assessed by Mexico. The results also indicate that tolls can provide a reliable revenue stream for international bridge infrastructure finance in Mexico.
\end{abstract}

Key Words: Tolls, Bridges, Mexico Border, Applied Econometrics.

\section{Acknowledgements}

Funding support for this research was provided by El Paso Electric Company, Hunt Communities, JPMorgan Chase Bank of El Paso, Wells Fargo Bank of El Paso, El Paso Water Utilities, Texas Department of Transportation, the James Foundation Scholarship Fund, and a UTEP College of Business Administration Faculty Research Grant. Helpful suggestions and comments were provided by Brian Kelley, Terry Clower, and two anonymous referees. Econometric research assistance was provided by Karen Fierro, Enedina Licerio, and Emmanuel Villalobos. 


\section{Tolls, Exchange Rates, and Northbound International Bridge Traffic from Mexico}

JEL Categories: M21, Business Economics; R15, Regional Econometrics

\section{Introduction}

Increased economic activity plus demographic expansion have combined to raise crossborder traffic over the international bridges that connect El Paso, Texas and Ciudad Juarez, Chihuahua, an area commonly referred to as the Borderplex. Econometric model simulations indicate that northbound international bridge crossings from Ciudad Juarez into El Paso are forecast to increase at steady paces at least through 2026 (Fullerton and Molina, 2007). While recent research has examined fluctuations in southbound traffic across these arteries (De Leon, Fullerton, and Kelley, 2009), northbound international bridge crossings from Ciudad Juarez into El Paso have heretofore not been analyzed utilizing econometric techniques. This research effort attempts to partially bridge that gap in the literature using an applied time series approach.

Autoregressive-moving average (ARIMA) transfer functions are used to model the three major traffic categories for these ports of entry: pedestrians, personal vehicles, and cargo vehicles. Several key variables are employed in the empirical analysis. Principal among them are the tolls charged by the Caminos y Puentes Federales de Ingresos y Servicios Conexos (CAPUFE) agency of the federal government in Mexico. Other variables that reflect economic conditions within the Borderplex are also used in the study. The sample period is January 1990 through December 2006 and monthly frequency data are utilized. The sample period is determined by data availability at CAPUFE. 
An overview of related studies is provided next section. That section is followed by a brief discussion of the data and methodology. Empirical results are discussed in the fourth section. Next, out-of-sample simulation results are presented to provide additional evidence of empirical reliability. Implications for regional economic development and suggestions for future research are provided in the conclusion.

\section{Literature Review}

Wuestefeld and Regan (1981) study the impact of toll increases on revenue streams and traffic flows. Elasticities are found to vary for each customer category, commercial, passenger, and so forth. Also, the burden of higher tolls will be treated as a cost of production and be at least partially passed onto distributors, and, subsequently, to consumers. Results suggest that toll increases generally result in increased revenue. Because of commuter profile heterogeneity, artery usage tends to be highly variable, suggesting that response to toll increases will also vary across facilities and markets.

Road pricing often involves other factors such as income, relative prices of alternate tolled facilities, and the characteristics of surrounding network roads (Minasian, 1979). Optimal road pricing is an elusive goal. That is in part because specific types of traffic react differently to tolls (Diamandis, Kouretas, and Tzanetos, 1997). Statistical analyses of the variable toll rate system indicate that passenger vehicles adjust more than any other traffic category to toll changes at different times during the day (Olszewski and Xie, 2005). Similar to Hirschman, McKnight, Pucher, Paaswell, and Berechman (1995), price elasticities with respect to tolls are 
found to be relatively low. Availability of non-tolled alternate routes tends to increase toll sensitivity, while business cycle upswings tend to reduce it (Matas and Raymond, 2003).

Not surprisingly, long run demand is typically more elastic than short run demand (Oum, Waters, and Yong, 1992). Tolls have periodically been employed as a means for reducing roadway congestion in certain areas while recovering a percentage of the costs associated with road construction, maintenance, and enhancements. When surplus toll revenue is generated, it is often applied to budgetary areas beyond the road grid (Ferrari, 2002). Willingness to pay by local residents can also influence the design of rates (Brownstone, Ghosh, Golob, Kazimi, and Van Amelsfort, 2003; Podgorksi and Kockelman, 2006). As congestion increases, consumer opinion becomes more favorable toward tolled motorways.

A small subset of the existing empirical literature examines international bridge traffic within the El Paso-Ciudad Juarez Borderplex. One of the early studies highlights the importance of currency fluctuations on cross-border traffic flows (Fullerton, 2000). Fullerton (2001) jointly incorporates regional and national business cycle indicators in the equations for northbound international bridge crossings from Ciudad Juarez to El Paso using annual frequency data. Fullerton and Tinajero (2002) employ time series transfer function methods to model monthly cross-border cargo vehicle flows into El Paso. Northbound cargo vehicle traffic is found to respond quickly to Borderplex and macroeconomic business cycle fluctuations, but that study does not include tolls charged at the Ysleta-Zaragoza port of entry due to data constraints. 
A subsequent study (Fullerton, 2004) discusses disruptions to bridge usage caused by administrative decisions taken after the September 2001 terrorist attacks in the eastern United States. Significant delays resulted from those decisions and caused traffic flows to change in statistically significant manners. Commuters often react to time consuming safety inspections at the international ports within the Borderplex by reducing the number of times they cross or switching their means of conveyance (Villegas, Gurian, Heyman, Mata, Falcone, Ostapowicz, Wilrigs, Petragnani, and Eisele, 2006). Concerns regarding commuting delays at cross-border delays are not unique to the Borderplex and also affect other ports of entry (Lin and Lin, 2001).

To date, the only empirical study of Borderplex international bridge usage to include tolls has been conducted for southbound traffic to Ciudad Juarez (De Leon, Fullerton, and Kelley, 2009). This study complements that earlier effort by using time series techniques to model the impact of tolls on northbound international bridge crossings from Ciudad Juarez into El Paso. As with the prior effort, regional business cycle and real exchange rate variables are also included in the analyses.

\section{Data and Methodology}

Data used in this study include northbound traffic at two international ports of entry. One is the Paso del Norte Bridge near downtown El Paso. The second is the Ysleta-Zaragoza Bridge on the eastern edge of the City of El Paso. Both bridges are tolled, but cargo vehicles cannot use the Paso del Norte structure. Pedestrians and passenger automobiles that cross the Paso del Norte Bridge include large numbers of students, workers, and shoppers. In addition to 
pedestrians and personal vehicles, cargo vehicles also use the Ysleta-Zaragoza port of entry. Because of its more remote location, 0.725 million pedestrians crossed the Ysleta-Zaragoza Bridge in 2006. That figure is less than 12 percent of the 6.188 million persons who crossed the Paso del Norte structure by foot that same year (Fullerton and Molina, 2007).

Monthly northbound bridge crossing statistics for these international ports of entry are reported by the United States Department of Homeland Security. The sample period utilized in this effort is January 1990 to December 2006. For the Paso del Norte Bridge, those data include total northbound pedestrians along with total northbound passenger vehicles. Total northbound cargo vehicles, passenger vehicles, and pedestrians are included for the Ysleta-Zaragoza Bridge. It has been projected that merchandise trade growth may soon lead to traffic spill-backs on roads near the latter structure (Ashur, Weissman, Perez, and Weissman, 2001).

Several other data series are included as potential explanatory variables in the study. Those exogenous regressors include Ciudad Juarez maquiladora employment, Mexico Industrial Production Index, El Paso non-agricultural employment, and a real exchange rate index for the peso. El Paso monthly employment data are reported by the United States Bureau of Labor Statistics (www.bls.gov). The Mexican industrial production index and Ciudad Juarez maquiladora employment data series are provided by the Instituto Nacional de Estadística Geografía e Informática (www.inegi.gob.mx). The real peso index is from the University of Texas at El Paso Border Region Modeling Project (www.utep.edu). 
The sample covers a 16-year period. It is sufficiently long enough to include all three business cycle phases (expansion, recession, recovery) for macroeconomic performance on both sides of the border. Growth in both countries causes the data series employed to be nonstationary (Fullerton, 2000). Given that, all series are differenced prior to estimation in order to induce stationarity. A battery of augmented Dickey-Fuller unit root and chi-squared Q-statistic tests confirm the stationarity of the differenced series (Asteriou and Hall, 2011).

Each northbound traffic series is analyzed using a linear transfer function (LTF) time series procedure. Cross correlation functions are used to identify potential lag structures for each equation. Because of the different series being analyzed, there is no a priori reason to anticipate that those lag structures will be identical. Subsequent to estimation, diagnostic statistics are used to evaluate model performance. Using model residuals, an autocorrelation function is estimated to distinguish autoregressive and moving average components. Those terms account for any systematic variation in the dependent variable not captured by the lags of the regressors. In general, the LTF equations previously developed for tolled southbound international bridge flows perform well (De Leon, Fullerton, and Kelley, 2009). The LTF models estimated without tolls data for northbound cross-border cargo traffic volumes also exhibit good econometric traits (Fullerton and Tinajero, 2002). An LTF with lagged explanatory variables, along with autoregressive and moving average components, can be expressed as follows:

1. $\mathrm{y}_{\mathrm{t}}=\theta_{0}+\sum_{i=1}^{p} \phi_{\mathrm{i}} \mathrm{y}_{\mathrm{t}-\mathrm{i}}+\sum_{j=1}^{q} \theta_{\mathrm{j}} \mathrm{e}_{\mathrm{t}-\mathrm{j}}+\sum_{a=1}^{n} \mathrm{~A}_{\mathrm{a}} \mathrm{x}_{\mathrm{t}-\mathrm{a}}+\sum_{b=1}^{k} \mathrm{~B}_{\mathrm{b}} \mathrm{z}_{\mathrm{t}-\mathrm{b}}+\mathrm{e}_{\mathrm{t}}$ 
LTFs are estimated for northbound automobile traffic on the Ysleta-Zaragoza Bridge (ELBYC), cargo vehicles crossing into El Paso over the Ysleta-Zaragoza Bridge (ELBYT), and northbound pedestrians crossings at the Ysleta-Zaragoza Bridge (ELBYW). Equations are also estimated for northbound automobile traffic at the Paso del Norte port of entry (ELBPC) and for pedestrians crossing the Paso del Norte Bridge (ELBPW) into downtown El Paso. Toll bridge demand within each equation is modeled as a function of lags of the corresponding inflation adjusted toll for each traffic category: pedestrian (RPEDT), passenger vehicles (RAUTOT), and cargo vehicles (RCARGOT), respectively. Demand is also estimated as a function of lags of Ciudad Juarez maquiladora employment (MAQEMP), the Mexican industrial production index (MXIPI), the real exchange rate (REXR), and El Paso employment (EPEMP). Lagged autoregressive (AR) and moving average (MA) components are also included in the specifications. The implicit function for traffic demand at each port of entry may be represented as follows:

2. $\quad$ Traffic $_{t}=\mathrm{f}\left(\right.$ Real Toll $\left.\mathrm{t}_{\mathrm{t}-\mathrm{i}}, \mathrm{MAQEMP}_{\mathrm{t}-\mathrm{j}}, \mathrm{MXIPI}_{\mathrm{t}-\mathrm{k}}, \mathrm{REXR}_{\mathrm{t}-\mathrm{m}}, \mathrm{EPEMP}_{\mathrm{t}-\mathrm{n}}, \mathrm{AR}_{\mathrm{t}-\mathrm{p}}, \mathrm{MA}_{\mathrm{t}-\mathrm{q}}\right)$
(-)
(+)
(+)
(?)
(+)

Arithmetic signs below Equation 2 indicate the hypothesized relationship between the various traffic categories at each bridge and each independent variable. Results from earlier studies indicate that inflation adjusted tolls tend to decrease traffic demand at international ports of entry situated within the Borderplex (De Leon, Fullerton, and Kelley, 2009). Ciudad Juarez maquiladora employment and El Paso employment serve as broad measures of regional business 
cycle conditions. Inclusion of El Paso employment also helps control for population growth during the sample period as both variables are positively correlated with each other (Fullerton and Barraza de Anda, 2008). At the national level, the Mexican Industrial Production Index is reflective of macroeconomic conditions south of the border that go beyond those associated with the in-bond export industry. The relationship between traffic demand and the real exchange rate index is ambiguous. When the peso weakens, Mexican consumers are less likely to travel into the city of El Paso as a result of decreased purchasing power, but residents from the north side of the border will benefit. Similarly, increased volumes of cross-border cargo traffic have been documented during periods of peso depreciation because the cost of doing business declines for international manufacturing firms (Fullerton, 2000).

Following LTF parameter estimation, out-of-sample simulation forecasts are generated in rolling 24-month increments over the January 2003 to December 2006 period for each bridge traffic series. The predictive accuracy of each simulation is evaluated relative to a random walk benchmark. Random walk (RW) forecasts are generated using the last actual sample observations for each traffic category. They have previously been shown to provide effective benchmarks against which to assess border region econometric forecast precision (Fullerton, 2004). That may be a consequence of relatively high unemployment plus the impact of currency market fluctuations on the local economy (West, 2003; Meese and Rogoff, 1983). Because of historic difficulties in projecting traffic flows, a comparative assessment of model forecast precision is a useful step to include (Flyvbjerg, Holm, and Buhl, 2005). 
LTF out-of-sample simulations and their corresponding random walk benchmarks are generated sequentially. The initial historical sample period for parameter estimation is defined from January 1990 to December 2002. The first simulation is then conducted from January 2003 to December 2004. Next, the historical sample period is extended by one month to include January 2003 and the new forecast period is February 2003 to January 2005. This rolling parameter estimation and forecast procedure is carried out successively through December 2006. It renders a total of 48 one-month-ahead forecasts, 47 two-month-ahead forecasts, 46 threemonth-ahead forecasts, and so forth.

Theil inequality coefficients provide the first measures employed to compare the relative precisions of the LTF and RW out-of-sample simulations. These coefficients are descriptive in nature and yield helpful information regarding basic forecast performance (Pindyck and Rubinfeld, 1998). Theil inequality coefficients, also known as U-statistics, are calculated using the formula shown in Equation 3

3.

$$
U=\frac{\sqrt{\frac{1}{n} \sum\left(P_{i}-A_{i}\right)^{2}}}{\sqrt{\frac{1}{n} \sum P_{i}^{2}}+\sqrt{\frac{1}{n} \sum A_{i}^{2}}}
$$

where $P_{i}$ are forecast values for the variable of interest during the $i^{\text {th }}$ period, $A_{i}$ are actual values, and $\mathrm{n}$ is the number of observations. The Theil U-coefficient scales the root mean square such that it will always lie between zero and one. A U-statistic of one indicates the worst degree of predictive inaccuracy, while zero represents the highest possible level of forecast precision. 
The second accuracy metric is based on the (AGS) error differential regression test developed by Ashley, Granger, and Schmalensee (1980). It is conducted at each individual step length. This formal test of predictive accuracy compares the error differentials taken from two competing forecasts. The null hypothesis tested is shown in Equation 4

4.

$$
\mathrm{H}_{0}: \operatorname{MSE}\left(\mathrm{e}_{1}\right)=\operatorname{MSE}\left(\mathrm{e}_{2}\right) \text {, }
$$

where MSE refers to the mean-squared error of two competing forecast errors, $e_{1}, e_{2}$. MSE( $\left.\mathrm{e}_{1}\right)$ represents the mean square error for a random-walk benchmark and $\operatorname{MSE}\left(\mathrm{e}_{2}\right)$ represents the mean square error of an LTF model. By defining

5.

$$
\Delta_{\mathrm{t}}=\mathrm{e}_{1 \mathrm{t}}-\mathrm{e}_{2 \mathrm{t}} \text { and } \sum_{\mathrm{t}}=\mathrm{e}_{1 \mathrm{t}}+\mathrm{e}_{2 \mathrm{t}}
$$

Equation 4 may be re-expressed in the following form,

6.

$$
\operatorname{MSE}\left(\mathrm{e}_{1}\right)-\operatorname{MSE}\left(\mathrm{e}_{2}\right)=[\operatorname{cov}(\Delta, \Sigma)]+\left[m\left(\mathrm{e}_{1}\right)^{2}-m\left(\mathrm{e}_{2}\right)^{2}\right],
$$

where cov denotes sample covariance for the simulation period and $m$ denotes sample mean. LTF forecasts will be judged as superior if the joint null hypothesis that $\mu(\Delta)=0$ and $\operatorname{cov}(\Delta, \Sigma)=$ 0 can be rejected in favour of the alternative hypotheses described below. Equation 6 gives rise to two regression equations that may be used to test whether the MSEs are significantly different. The signs of the error means are used in order to determine to structure of the regression equation employed.

When the error means are of the same sign, the regression equation used to test the joint null hypothesis is given by: 
where $u_{t}$ is a randomly distributed error term. The test for $\mu(\Delta)=0$ involves interpretation of the parameter estimate for $\beta_{1}$. The test for $\operatorname{cov}(\Delta, \Sigma)=0$ involves the estimated coefficient for $\beta_{2}$.

When a positive value for $\beta_{2}$ results, the variance of the random walk forecast errors $\left(e_{1}\right)$ will always be greater than the variance of the LTF forecast errors $\left(e_{2}\right)$. A significantly positive $\beta_{2}$ will indicate LTF model superiority. The sign of the error means dictates the interpretation of $\beta_{1}$. When both error means are positive, LTF forecast superiority occurs when the joint null hypothesis that $\beta_{1}=\beta_{2}=0$ is rejected in favour of the alternative hypothesis that both are nonnegative and at least one is positive. However, the LTF forecast cannot be considered more precise than its random walk counterpart if either $\beta_{1}$ or $\beta_{2}$ are significantly negative. Furthermore, a one tailed t-test can be performed to test for significance in cases where one coefficient is insignificantly negative and the other is positive. When both parameter estimates are positive a four-pronged F-test can be used to test that both are statistically different from zero. Given that, the true significance that both estimates are positive will not be more than half the probability obtained from the F distribution (Ashley, Granger, and Schmalensee, 1980).

Although Equation 7 may still be used to test the null hypothesis when both error means are negative, the interpretation of $\beta_{1}$ changes. In such a case, if $\beta_{1}$ is found to be significantly negative, and $\beta_{2}$ is either insignificant or significantly positive, the LTF forecasts are superior. The RW walk forecasts are more precise when a significantly positive $\beta_{1}$ results. 
A different regression equation must be employed to test the null hypothesis in Equation 4 when the forecast error means are of opposite signs. Under this circumstance, the dependent variable becomes the sum of the forecast errors:

8. $\quad \sum_{\mathrm{t}}=\beta_{1}+\beta_{2}\left[\Delta_{\mathrm{t}}-m\left(\Delta_{\mathrm{t}}\right)\right]+\mathrm{u}_{\mathrm{t}}$.

As before, if $\beta_{1}=\beta_{2}=0$, the test fails to reject the null hypothesis in Equation 4. The interpretation of the $\beta_{2}$ coefficient is the same, but interpretation of the $\beta_{1}$ now depends on the sign of each error mean.

When the RW has a negative error mean and the LTF has a positive error mean, a significantly negative $\beta_{1}$ with $\beta_{2}$ insignificant or significantly positive points to LTF forecast superiority. In addition, the LTF forecasts are more accurate if an insignificant $\beta_{1}$ is exhibited along with a significantly positive $\beta_{2}$. The RW forecasts display greater precision when $\beta_{1}$ is significantly positive or $\beta_{2}$ is significantly negative.

Conversely, the RW may display a positive error mean while the LTF forecast error mean is negative. In this case, the $\mathrm{RW}$ forecasts are deemed superior if either $\beta_{1}$ or $\beta_{2}$ are significantly negative. The LTF predictions are favored when a significantly positive $\beta_{1}$ with a significantly positive or insignificant $\beta_{2}$ are displayed (Ashley, Granger, and Schmalensee 1980; Kolb and Stekler 1993). 
The third metric for accuracy comparison between these two sets of predictions involves a non-parametric t-test proposed by Diebold and Mariano (1995). This methodology is outlined in Equation 9.

9.

$$
\begin{aligned}
& \left(\text { RWrmse }_{t}-\text { LTFrmse }_{t}\right)=\theta_{0}+V_{t}, \text { where } \\
& V_{t}=\sum_{i=1}^{p} \phi_{i} V_{t-1}+\sum_{j=1}^{q} \theta_{j} U_{t-j}+U_{t}, \text { and } \\
& \left(\text { RWrmse }_{t}-\text { LTFrmse }_{t}\right)=\theta_{0}+\sum_{i=1}^{p} \phi_{i} V_{t-1}+\sum_{j=1}^{q} \theta_{j} U_{t-j}+U_{t}
\end{aligned}
$$

where:

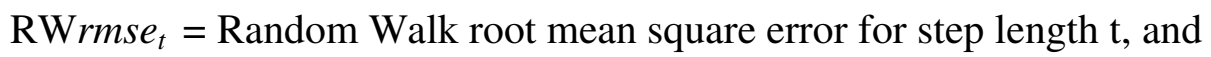

$\mathrm{LTFrmse}_{t}=\mathrm{LTF}$ root mean square error for step length $\mathrm{t}$.

As shown, the differences between the RW and LTF RMSEs at different step lengths are regressed against an intercept term. Interpretation of the results depends upon the sign of the constant term. If it is statistically significant and positive, the LTF predictions are most accurate. Alternatively, a statistically significant negative intercept term implies that the RW forecasts are more precise. If the intercept term is not statistically different from zero, then neither method can be regarded as more accurate than the other.

\section{Empirical Estimation Results}

Tables 1 through 5 summarize the results for the LTF equations estimated for each northbound bridge traffic category. All series are differenced prior to estimation due to the presence of trend non-stationarity. Price elasticities of demand are also calculated at the two 
ports of entry for each traffic category. Unlike Fullerton (2004), qualitative variables are not included to account for intervention shifts subsequent to the $9 / 11$ attacks that altered bridge inspection practices. Traffic flows across the bridges in question may have adapted sufficiently by 2006 that inclusion of step dummies is no longer necessary (Charemza and Deadman, 1997).

\section{Table 1. Ysleta-Zaragoza Northbound Pedestrians (ELBYW)}

\begin{tabular}{lllll} 
Variable & Coefficient & Std. Error & t-statistic & Probability \\
& & & & \\
Constant & $-9.35 \mathrm{E}-05$ & 0.0005 & -0.2041 & 0.8385 \\
RPEDT & -0.4896 & 0.6139 & -0.7976 & 0.4261 \\
MAQEMP(-6) & $1.23 \mathrm{E}-08$ & $1.66 \mathrm{E}-07$ & 0.0739 & 0.9412 \\
MXIPI(-4) & 0.0002 & 0.0001 & 1.6743 & 0.0958 \\
REXR(-2) & -0.0003 & 0.0001 & -2.0758 & 0.0393 \\
EPEMP(-10) & $3.07 \mathrm{E}-07$ & $2.67 \mathrm{E}-07$ & 1.1500 & 0.2516 \\
AR(1) & -0.3412 & 0.0705 & -4.8396 & 0.0000 \\
& & & \\
R-Squared & 0.1760 & Mean Dep. Var. & 0.0002 \\
Adj. R-Sq. & 0.1493 & Std. Dvn. Dep. Var. & 0.0084 \\
Std. Err. Reg. & 0.0077 & Akaike Info. Crit. & -6.8566 \\
Sum Sq. Resid. & 0.0110 & \multicolumn{2}{c}{ Schwarz Info. Crit. } & -6.7378 \\
Log-Likelihood & 665.2333 & \multicolumn{2}{c}{ F-Statistic } & 6.5862 \\
Durbin-Watson & 2.1749 & \multicolumn{2}{c}{ Prob. (F-Stat) } & 0.000003
\end{tabular}

Ysleta-Zaragoza Northbound Pedestrians Toll Elasticity $\quad-2.258$

Table 1 reports the results for pedestrians crossing into El Paso via the Ysleta-Zaragoza Bridge. The results suggest that an increase in tolls leads to an immediate decrease in pedestrian traffic at this port of entry. Ciudad Juarez maquiladora employment and the Mexico Industrial Production Index are positively correlated with northbound pedestrian traffic at the Zaragoza Bridge. Those two relationships suggest that northbound pedestrian volumes will increase during economic expansions south of the border. A negative relationship between pedestrian 
traffic flows and the real exchange rate is exhibited. As such, peso depreciation will cause northbound pedestrian traffic to decrease moderately.

It should be noted that five of the seven parameters in Table 1, including the toll coefficient, fail to satisfy the 5-percent significance criterion. Because the F-statistic is significant at the 1-percent level, it potentially reflects the presence of multicollinearity within the sample (Fullerton and Tinajero, 2002). Tests with alternative specifications do not generate any evidence in favor of that possibility. Beyond that, none of the variance inflation factors (VIFs) calculated from auxiliary regression equations estimated for each of the explanatory variables are greater than 1.10 , well below what is traditionally viewed as problematic (Asteriou and Hall, 2011). The price elasticity is calculated at -2.258 , implying that northbound foot traffic across this artery is very responsive to real changes in the toll. However, the insignificant $t$ statistic for the price variable is more in line with the hypothesis that tolls will influence traffic volumes very little when applied to bridges or other infrastructure that are relatively distant from other alternatives (Wuestefeld and Regan, 1981; Loo, 2003).

Estimation results for northbound automobiles at the Ysleta-Zaragoza Bridge are reported in Table 2. Tolls exhibit a statistically significant negative impact on the volume of cars headed into El Paso across this bridge. Ciudad Juarez maquiladora employment and the Mexico Industrial Production Index are positively correlated with Ysleta-Zaragoza Bridge northbound automobile traffic. A negative relationship is reported between the real exchange rate and northbound passenger vehicle flows. The negative sign of the real exchange rate coefficient implies that decreased purchasing power south of the border reduces the number of automobiles 
entering El Paso at this port of entry. That result is not surprising as many commuters traverse this point of entry en route to the various shopping centers located in East El Paso. A positive relationship exists between El Paso employment and northbound automobile traffic at this bridge. In line with empirical results documented for other metropolitan economies (Cervero, 1990), the estimated price elasticity of -0.50 indicates that traffic flows at this bridge are relatively insensitive to changes in the toll. Increases in the tariff will not be offset by traffic volume reductions, implying that revenues collected by CAPUFE will rise.

Table 2. Ysleta-Zaragoza Northbound Automobiles (ELBYC)

\begin{tabular}{lllcl} 
Variable & Coefficient & Std. Error & t-statistic & Probability \\
& & & & \\
Constant & -0.0010 & 0.0001 & -7.3983 & 0.0000 \\
RAUTOT & -0.7144 & 0.1702 & -4.1980 & 0.0000 \\
MAQEMP & $2.09 \mathrm{E}-07$ & $1.23 \mathrm{E}-07$ & 1.7022 & 0.0905 \\
MXIPI(-12) & 0.0009 & 0.0003 & 2.6999 & 0.0076 \\
REXR(-2) & -0.0039 & 0.0002 & -1.7460 & 0.0825 \\
EPEMP(-8) & $3.37 \mathrm{E}-06$ & $6.15 \mathrm{E}-07$ & 5.4864 & 0.0000 \\
AR(1) & -0.7066 & 0.0720 & -9.8142 & 0.0000 \\
AR(2) & 0.2810 & 0.0725 & 3.8775 & 0.0001 \\
MA(2) & -0.9782 & 0.0138 & -70.9619 & 0.0000 \\
& & & \\
R-Squared & 0.4142 & Mean Dep. Var. & 0.0009 \\
Adj. R-Sq. & 0.3882 & \multicolumn{2}{c}{ Std. Dvn. Dep. Var. } & 0.0254 \\
Std. Err. Reg. & 0.0199 & \multicolumn{2}{c}{ Akaike Info. Crit. } & -4.9546 \\
Sum Sq. Resid. & 0.0709 & \multicolumn{2}{c}{ Schwarz Info. Crit. } & -4.8002 \\
Log-Likelihood & 477.2046 & F-Statistic & 15.9107 \\
Durbin-Watson & 2.0099 & \multicolumn{2}{c}{ Prob. (F-Stat) } & 0.000001
\end{tabular}

Ysleta-Zaragoza Northbound Automobiles Toll Elasticity $\quad-\mathbf{0 . 5 0 2}$

Table 3 reports the results of the equation estimated for northbound cargo vehicles at the Ysleta-Zaragoza Bridge. Tolls are negatively correlated with cargo vehicle traffic traveling into 
El Paso at this port of entry. Maquiladora employment and the Mexico Industrial Production Index positively impact northbound cargo vehicle flow in statistically significant manners. Contrary to the results reported in Tables 1 and 2, the sign of the real exchange rate coefficient implies that northbound cargo vehicle traffic within the Borderplex increase when the peso depreciates. Earlier results have also documented increased northbound traffic flows during periods of peso depreciation (Fullerton, 2000).

\begin{tabular}{|c|c|c|c|c|}
\hline Variable & Coefficient & Std. Error & t-statistic & Probability \\
\hline Constant & $-7.74 \mathrm{E}-05$ & 0.0001 & -0.5784 & 0.5637 \\
\hline RCARGOT(-1) & -0.0029 & 0.0038 & -0.7640 & 0.4459 \\
\hline MAQEMP & $1.52 \mathrm{E}-07$ & $5.52 \mathrm{E}-08$ & 2.7556 & 0.0065 \\
\hline MXIPI(-3) & 0.0001 & 4.94E-05 & 2.3682 & 0.0189 \\
\hline $\operatorname{REXR}(-6)$ & $8.81 \mathrm{E}-05$ & $4.47 \mathrm{E}-05$ & 1.9699 & 0.0504 \\
\hline $\operatorname{EPEMP}(-11)$ & $2.18 \mathrm{E}-07$ & $9.17 \mathrm{E}-08$ & 2.3816 & 0.0183 \\
\hline $\mathrm{AR}(1)$ & -0.4581 & 0.0748 & -6.1274 & 0.0000 \\
\hline $\operatorname{AR}(2)$ & -0.1739 & 0.0785 & -2.2148 & 0.0280 \\
\hline R-Squared & 0.3187 & \multicolumn{2}{|c|}{ Mean Dep. Var. } & 0.0001 \\
\hline Adj. R-Sq. & 0.2925 & \multicolumn{2}{|c|}{ Std. Dvn. Dep. Var. } & 0.0032 \\
\hline Std. Err. Reg. & 0.0027 & \multicolumn{2}{|c|}{ Akaike Info. Crit. } & -8.9417 \\
\hline Sum Sq. Resid. & 0.0013 & \multicolumn{2}{|c|}{ Schwarz Info. Crit. } & -8.8050 \\
\hline Log-Likelihood & 857.4612 & \multicolumn{2}{|c|}{ F-Statistic } & 12.1637 \\
\hline Durbin-Watson & 2.0098 & \multicolumn{2}{|c|}{ Prob. (F-Stat) } & 0.000001 \\
\hline
\end{tabular}

Ysleta-Zaragoza Northbound Cargo Vehicles Toll Elasticity $\quad \mathbf{- 0 . 1 1 7}$

Three of the eight parameters estimated in this equation are insignificant at the 5-percent significance level. With an F-statistic that is significant at the 1-percent level, multicollinearity may be present in the sample. Once again, experimentation with alternative specifications did not, however, indicate that to be the case. Similarly, auxiliary regressions for each of the explanatory variables failed to yield any VIFs that exceed 1.10. Accordingly, cargo traffic using 
this bridge seems to respond minimally to changes in tolls. The computed price elasticity is 0.117 implying that northbound cargo vehicle traffic is highly inelastic with respect toll rate changes. That result is in line with arguments that commercial vehicles may be less responsive to fare increases since their trips are typically non-optional (Wuestefeld and Regan, 1981).

Table 4. Paso del Norte Northbound Automobiles (ELBPC)

\begin{tabular}{|c|c|c|c|c|}
\hline Variable & Coefficient & Std. Error & t-statistic & Probability \\
\hline Constant & -0.0024 & 0.0008 & -2.8380 & 0.0051 \\
\hline RAUTOT(-7) & -0.4621 & 0.4625 & -0.9993 & 0.3190 \\
\hline MAQEMP(-4) & 8.78E-07 & $4.35 \mathrm{E}-07$ & 2.0176 & 0.0451 \\
\hline MXIPI(-12) & 0.0017 & 0.0005 & 3.1745 & 0.0018 \\
\hline $\operatorname{REXR}(-2)$ & -0.0007 & 0.0005 & -1.3496 & 0.1788 \\
\hline $\operatorname{EPEMP}(-8)$ & $2.57 \mathrm{E}-06$ & $1.07 \mathrm{E}-06$ & 2.4144 & 0.0168 \\
\hline $\operatorname{AR}(1)$ & -0.4860 & 0.0727 & -6.6810 & 0.0000 \\
\hline $\operatorname{AR}(2)$ & -0.3893 & 0.0782 & -4.9792 & 0.0000 \\
\hline $\mathrm{MA}(3)$ & -0.4110 & 0.0793 & -5.1857 & 0.0000 \\
\hline R-Squared & 0.3224 & \multicolumn{2}{|c|}{ Mean Dep. Var. } & -0.0002 \\
\hline Adj. R-Sq. & 0.2922 & \multicolumn{2}{|c|}{ Std. Dvn. Dep. Var. } & 0.0368 \\
\hline Std. Err. Reg. & 0.0310 & \multicolumn{2}{|c|}{ Akaike Info. Crit. } & -4.0647 \\
\hline Sum Sq. Resid. & 0.1727 & \multicolumn{2}{|c|}{ Schwarz Info. Crit. } & -3.9104 \\
\hline Log-Likelihood & 393.1181 & \multicolumn{2}{|c|}{ F-Statistic } & 10.7030 \\
\hline Durbin-Watson & 2.0010 & \multicolumn{2}{|c|}{ Prob. (F-Stat) } & 0.000001 \\
\hline
\end{tabular}

\section{Paso Del Norte Northbound Automobile Toll Elasticity $\quad \mathbf{- 0 . 2 2 6}$}

A set of linear transfer function ARIMA equations are also estimated for the two traffic categories allowed on the Paso del Norte Bridge. Table 4 reports the results for northbound automobile crossings at this bridge. Similar to the results reported in Tables 1 through 3 , tolls are negatively correlated with northbound automobile traffic. Maquiladora employment and the Mexico Industrial Production Index are statistically significant and positively correlated with northbound automobile traffic volumes. Because of its proximity to the downtown El Paso retail 
district, many northbound commuters navigate this bridge to engage in various shopping activities.

The REXR coefficient in Table 4 suggests that, during periods of peso depreciation, northbound automobile traffic flows will decrease. Although the toll and exchange rate parameters do not satisfy the 5-percent significance criterion, experimentation with alternative specifications indicates that multicollinearity may affect the magnitudes of their respective tstatistics. Auxiliary regression VIFs for the various independent variables utilized, however, all fall below 1.35, overturning that argument (Asteriou and Hall, 2011). The EPEMP coefficient indicates that strong employment conditions north of the border are positively correlated with increases in northbound automobile traffic. A price elasticity coefficient of -0.226 implies that northbound automobile traffic at this port of entry is relatively non-responsive to real (and nominal) toll rate fluctuations. That result potentially reflects the absence of nearby alternatives for crossing the border (Hirschman, McKnight, Pucher, Paaswell, and Berechman, 1995; Matas and Raymond, 2003). It is very much in line with elasticity estimates calculated for other regions of the world (Graham and Glaister, 2004).

Table 5 presents the results of the equation estimated for northbound pedestrians at the Paso del Norte Bridge. Although the real toll rate coefficient fails to meet the 5-percent significance criterion, its negative relationship with the independent variable is in line with theoretical expectations. Whereas tolls seemed to exert an immediate affect on northbound pedestrian flows at the Ysleta-Zaragoza Bridge, the lag on the toll coefficient for this bridge indicates a delayed response for downtown foot traffic. While there is no reason to anticipate 
identical lagged responses for pedestrian tolls for both bridges, the distinct results obtained are striking.

In all, four of the eight parameters in this equation fail to satisfy the 5-percent significance criterion. Equation re-estimation does not, however, indicate that multicollinearity affects the parameter estimates shown in Table 5. The latter point is also corroborated by VIF statistics that all fall below 1.10 for each of the right-hand-side regressors. Maquiladora employment and the Mexico Industrial Production Index are positively correlated with pedestrian traffic crossing into El Paso at the Paso del Norte Bridge. The sign on the real exchange rate coefficient implies that fewer pedestrians will cross into El Paso at this port of entry when the peso weakens relative to the dollar. El Paso employment is also found to be positively correlated with Paso del Norte northbound pedestrian volumes. The elasticity coefficient indicates that northbound pedestrian traffic reacts very little to changes in the toll rate at this bridge.

Table 5. Paso del Norte Northbound Pedestrians (ELBPW)

\begin{tabular}{|c|c|c|c|c|}
\hline Variable & Coefficient & Std. Error & t-statistic & Probability \\
\hline Constant & -0.0021 & 0.0042 & -0.5069 & 0.6128 \\
\hline RPEDT(-11) & -1.5033 & 5.3850 & -0.2792 & 0.7804 \\
\hline MAQEMP(-10) & 2.97E-07 & $1.59 \mathrm{E}-06$ & 0.1865 & 0.8523 \\
\hline MXIPI(-9) & 0.0030 & 0.0014 & 2.1781 & 0.0307 \\
\hline REXR(-4) & -0.0015 & 0.0013 & -1.0982 & 0.2736 \\
\hline EPEMP(-12) & $5.96 \mathrm{E}-06$ & $2.90 \mathrm{E}-06$ & 2.0527 & 0.0415 \\
\hline $\mathrm{AR}(1)$ & -0.3716 & 0.0718 & -5.1768 & 0.0000 \\
\hline $\operatorname{AR}(2)$ & -0.3098 & 0.0705 & -4.3960 & 0.0000 \\
\hline R-Squared & 0.2277 & \multicolumn{2}{|c|}{ Mean Dep. Var. } & 0.0017 \\
\hline Adj. R-Sq. & 0.1979 & \multirow{2}{*}{\multicolumn{2}{|c|}{$\begin{array}{l}\text { Std. Dvn. Dep. Var. } \\
\text { Akaike Info. Crit. }\end{array}$}} & 0.0926 \\
\hline Std. Err. Reg. & 0.0829 & & & -2.0100 \\
\hline
\end{tabular}




$\begin{array}{llll}\text { Sum Sq. Resid. } & 1.2453 & \text { Schwarz Info. Crit. } & -1.9626 \\ \text { Log-Likelihood } & 206.43 & \text { F-Statistic } & 7.6256 \\ \text { Durbin-Watson } & 2.0955 & \text { Prob. (F-Stat) } & 0.000001\end{array}$

\section{Paso del Norte Northbound Pedestrian Toll Elasticity $\quad \mathbf{- 0 . 1 1 8}$}

Tables 1 through 5 report the results of LTF time series equations estimated for three major traffic categories at two distinct tolled facilities. As has been documented for other regional transportation systems, tolls are negatively correlated with northbound traffic volumes, but not always at the 5-percent significance level (Mrkaic and Pezdir, 2008). The negative signs are not surprising, as rising tolls generally lead to a decrease in traffic demand at tolled facilities (Wuestefeld and Regan, 1981). Of the elasticity coefficients calculated, results indicate that northbound pedestrian flow at the Ysleta-Zaragoza Bridge is most responsive to changes in the toll rate. Previous studies have documented high elasticities at locations where commuters enjoy the option to navigate non-tolled facilities when rates at tolled facilities rise (Hirschman, McKnight, Pucher, Paaswell, and Berechman, 1995; Matas and Raymond 2003). Given the distance to the nearest untolled structure linking the two sides of the Borderplex, this possibility is probably not very likely. The presence of good shopping alternatives in this section of Ciudad Juarez may play a more pivotal role in this result. In line with prior regional transportation research, the elasticities for the various user categories exhibit substantial variability (Diamandis, Kouretas, and Tzanetos, 1997).

One final observation regarding the estimation results should also be made. Namely, the lag structures differ substantially between each equation. Because of differences between the geographic locations (downtown vs. urban periphery) of the two bridges and the distinct natures 
of the series modeled (pedestrian, light vehicles, large cargo trucks), some variation is not surprising. The extent to which this is the case in these results mirrors the lag structure heterogeneity documented in earlier work (Fullerton and Tinajero, 2002; De Leon, Fullerton, and Kelley, 2009) and helps underscore the importance of allowing for this possibility in future work of this nature.

\section{Out-of-Sample Simulation Results}

It is well known in applied econometrics that good fits do not guarantee out-of-sample simulation and/or forecast precision, especially for regions with relatively high rates of unemployment (West, 2003). That possibility has previously been documented for border air and surface transportation activities using annual frequency data from a large structural econometric model (Fullerton, 2004). Given that, a series of out-of-sample simulation exercises are completed for each of the LTF time series equations as discussed above. The outcomes of these comparative steps follow.

Table 6 summarizes the results of out-of-sample simulations for northbound pedestrian flows across the Ysleta-Zaragoza bridge on the east side of El Paso. A comparison of the LTF and RW forecast accuracy ranking for this bridge traffic category offers mixed results. In 17 of the 24 individual step lengths the random walk benchmark is favoured by the U-statistic. The LTF equation yields a lower U-statistic for the one-month, two-month, three-month, four-month, six-month, seven-month, and eleven-month ahead forecasts. The outcome of the AGS test points to RW superiority in 13 of the 24 individual step-lengths. Of the remaining 11 step-lengths, 10 
are statistically inconclusive. For the three-month ahead forecast, the AGS procedure favors the LTF approach. The DM t-test for RMSE equality across all 24 step-lengths is also inconclusive. While these results are not conclusive, the evidence in Table 6 does seem to favor the RW extrapolations at step-lengths greater than eleven months.

Table 6. Ysleta-Zaragoza Northbound Pedestrians Forecast Accuracy Rankings

\begin{tabular}{|c|c|c|c|c|}
\hline $\begin{array}{l}\text { Step } \\
\text { Length } \\
\end{array}$ & $\begin{array}{l}\text { Number of } \\
\text { Observations }\end{array}$ & U-statistic & $\begin{array}{l}\text { AGS Error } \\
\text { Differential }\end{array}$ & $\begin{array}{l}\text { DM RMSE } \\
\text { Differential } \\
\end{array}$ \\
\hline 1-Month & 48 & $\mathrm{LTF}$ & Inconclusive & Inconclusive \\
\hline 2-Months & 47 & LTF & Inconclusive & \\
\hline 3-Months & 46 & LTF & LTF & \\
\hline 4-Months & 45 & LTF & Inconclusive & \\
\hline 5-Months & 44 & RW & RW & \\
\hline 6-Months & 43 & LTF & Inconclusive & \\
\hline 7-Months & 42 & LTF & Inconclusive & \\
\hline 8-Months & 41 & RW & RW & \\
\hline 9-Months & 40 & RW & RW & \\
\hline 10-Months & 39 & RW & Inconclusive & \\
\hline 11-Months & 38 & LTF & Inconclusive & \\
\hline 12-Months & 37 & RW & RW & \\
\hline 13-Months & 36 & RW & $\mathrm{RW}$ & \\
\hline 14-Months & 35 & RW & RW & \\
\hline 15-Months & 34 & RW & RW & \\
\hline 16-Months & 33 & RW & Inconclusive & \\
\hline 17-Months & 32 & RW & RW & \\
\hline 18-Months & 31 & RW & Inconclusive & \\
\hline 19-Months & 30 & RW & RW & \\
\hline 20-Months & 29 & RW & RW & \\
\hline 21-Months & 28 & RW & RW & \\
\hline 22-Months & 27 & RW & $\mathrm{RW}$ & \\
\hline 23-Months & 26 & RW & Inconclusive & \\
\hline 24-Months & 25 & RW & RW & \\
\hline
\end{tabular}

Sample Period: January 2003 - December 2006.

LTF, autoregressive integrated moving average linear transfer function.

RW, random walk.

RMSE, root mean square error.

AGS, error difference regression test.

DM, non-parametric RMSE difference t-test. 
Light vehicles comprise the second northbound traffic category at the Ysleta-Zaragoza point of entry. As shown in Table 7, out-of-sample simulation results are more decisive than those reported for northbound pedestrians at this bridge. Across all individual 24 step-lengths the LTF forecasts yield lower U-statistics than their corresponding RW benchmarks. Also notable is that the AGS test statistics for each step-length uniformly point to superior LTF predictive accuracy. Lastly, the DM t-test further indicates statistically significant smaller forecast errors for the LTF out-of-sample simulations across all step-lengths.

Table 7. Ysleta-Zaragoza Northbound Automobiles Forecast Accuracy Rankings

\begin{tabular}{lllll}
$\begin{array}{l}\text { Step } \\
\text { Length }\end{array}$ & $\begin{array}{l}\text { Number of } \\
\text { Observations }\end{array}$ & U-statistic & $\begin{array}{l}\text { AGS Error } \\
\text { Differential }\end{array}$ & $\begin{array}{c}\text { DM RMSE } \\
\text { Differential }\end{array}$ \\
\hline 1-Month & 48 & LTF & LTF & LTF \\
2-Months & 47 & LTF & LTF & \\
3-Months & 46 & LTF & LTF & \\
4-Months & 45 & LTF & LTF & \\
5-Months & 44 & LTF & LTF & \\
6-Months & 43 & LTF & LTF & \\
7-Months & 42 & LTF & LTF & \\
8-Months & 41 & LTF & LTF & \\
9-Months & 40 & LTF & LTF & \\
10-Months & 39 & LTF & LTF & \\
11-Months & 38 & LTF & LTF & \\
12-Months & 37 & LTF & LTF & \\
13-Months & 36 & LTF & LTF & \\
14-Months & 35 & LTF & LTF & \\
15-Months & 34 & LTF & LTF & \\
16-Months & 33 & LTF & LTF & \\
17-Months & 32 & LTF & LTF & \\
18-Months & 31 & LTF & LTF & \\
19-Months & 30 & LTF & LTF & \\
20-Months & 29 & LTF & LTF & \\
21-Months & 28 & LTF & LTF & \\
22-Months & 27 & LTF & LTF
\end{tabular}


23-Months $26 \quad$ LTF LTF

24-Months 25 LTF LTF

Sample Period: January 2003 - December 2006.

LTF, autoregressive integrated moving average linear transfer function.

RW, random walk.

RMSE, root mean square error.

AGS, error difference regression test.

DM, non-parametric RMSE difference t-test.

The Ysleta-Zaragoza Bridge is also traversed by larges volumes of cargo vehicle traffic crossing into El Paso from industrial parks in northern Mexico. Similar to the forecast accuracy rankings reported for northbound automobiles at this major artery, the results in Table 8 underscore relative LTF forecast superiority. The LTF forecasts obtain lower inequality coefficients at all 24 individual step-lengths. Similarly, the AGS test outcomes across each of the 24 step-lengths all point to relative RW forecast imprecision. The one exception to this pattern of outcomes is provided by the DM t-test, which in this case is inconclusive.

Table 8. Ysleta-Zaragoza Northbound Cargo Vehicles Forecast Accuracy Rankings

\begin{tabular}{lllll}
$\begin{array}{l}\text { Step } \\
\text { Length }\end{array}$ & $\begin{array}{l}\text { Number of } \\
\text { Observations }\end{array}$ & U-statistic & $\begin{array}{l}\text { AGS Error } \\
\text { Differential }\end{array}$ & $\begin{array}{l}\text { DM RMSE } \\
\text { Differential }\end{array}$ \\
\hline 1-Month & 48 & LTF & LTF & Inconclusive \\
2-Months & 47 & LTF & LTF & \\
3-Months & 46 & LTF & LTF & \\
4-Months & 45 & LTF & LTF & \\
5-Months & 44 & LTF & LTF & \\
6-Months & 43 & LTF & LTF & \\
7-Months & 42 & LTF & LTF & \\
8-Months & 41 & LTF & LTF & \\
9-Months & 40 & LTF & LTF & \\
10-Months & 39 & LTF & LTF & \\
11-Months & 38 & LTF & LTF & \\
12-Months & 37 & LTF & LTF & \\
13-Months & 36 & LTF & LTF & \\
14-Months & 35 & LTF & LTF &
\end{tabular}




$\begin{array}{llll}\text { 15-Months } & 34 & \text { LTF } & \text { LTF } \\ \text { 16-Months } & 33 & \text { LTF } & \text { LTF } \\ \text { 17-Months } & 32 & \text { LTF } & \text { LTF } \\ \text { 18-Months } & 31 & \text { LTF } & \text { LTF } \\ \text { 19-Months } & 30 & \text { LTF } & \text { LTF } \\ \text { 20-Months } & 29 & \text { LTF } & \text { LTF } \\ \text { 21-Months } & 28 & \text { LTF } & \text { LTF } \\ \text { 22-Months } & 27 & \text { LTF } & \text { LTF } \\ \text { 23-Months } & 26 & \text { LTF } & \text { LTF } \\ \text { 24-Months } & 25 & \text { LTF } & \text { LTF }\end{array}$

Sample Period: January 2003 - December 2006.

LTF, autoregressive integrated moving average linear transfer function.

RW, random walk.

RMSE, root mean square error.

AGS, error difference regression test.

DM, non-parametric RMSE difference t-test.

Results for the northbound automobile forecasts for the Paso del Norte port of entry near downtown El Paso are reported in Table 9. They are decidedly mixed. For 21 of the 24 individual step-lengths, the LTF U-statistics are greater than those associated with their respective RW counterparts. The DM t-test also suggests that the RW benchmark simulations are collectively more accurate than those of the LTF time series equations. Interestingly, the AGS test outcomes for 16 of the individual step-lengths contradict the U-statistic results. For each of those 16 step-lengths, the AGS equations exhibit statistically significant positive $\beta_{2}$ slope coefficients, while the signs of the LTF and RW error means are both positive. That combination points to comparative LTF forecast superiority. For the remaining six step-lengths, the AGS regression results are statistically inconclusive. Given this combination of empirical evidence, it is difficult to determine whether the LTF simulations are more reliable than the RW benchmarks.

Table 9. Paso del Norte Northbound Automobiles Forecast Accuracy Rankings 


\begin{tabular}{lllll}
$\begin{array}{l}\text { Step } \\
\text { Length }\end{array}$ & $\begin{array}{l}\text { Number of } \\
\text { Observations }\end{array}$ & U-statistic & $\begin{array}{l}\text { AGS Error } \\
\text { Differential }\end{array}$ & $\begin{array}{c}\text { DM RMSE } \\
\text { Differential }\end{array}$ \\
\hline 1-Month & 48 & LTF & Inconclusive & RW \\
2-Months & 47 & RW & Inconclusive & \\
3-Months & 46 & RW & LTF & \\
4-Months & 45 & RW & LTF & \\
5-Months & 44 & RW & LTF & \\
6-Months & 43 & RW & LTF & \\
7-Months & 42 & RW & Inconclusive & \\
8-Months & 41 & RW & LTF & \\
9-Months & 40 & RW & LTF & \\
10-Months & 39 & RW & LTF & \\
11-Months & 38 & RW & LTF & \\
12-Months & 37 & RW & Inconclusive & \\
13-Months & 36 & RW & LTF & \\
14-Months & 35 & RW & LTF & \\
15-Months & 34 & RW & LTF & \\
16-Months & 33 & RW & LTF & \\
17-Months & 32 & RW & LTF & \\
18-Months & 31 & RW & LTF & \\
19-Months & 30 & RW & Inconclusive & \\
20-Months & 29 & LTF & LTF & \\
21-Months & 28 & RW & LTF & \\
22-Months & 27 & LTF & LTF & \\
23-Months & 26 & RW & LTF & \\
24-Months & 25 & RW & Inconclusive &
\end{tabular}

Sample Period: January 2003 - December 2006.

LTF, autoregressive integrated moving average linear transfer function.

$\mathrm{RW}$, random walk.

RMSE, root mean square error.

AGS, error difference regression test.

DM, non-parametric RMSE difference t-test.

Table 10 reports the out-of-sample simulation rankings for northbound pedestrian bridge traffic at the Paso del Norte port of entry. Here, the LTF forecasts are favored by the U-statistic at step-lengths 1 through 11, and again at the 13 and 14 month-ahead projections. The inequality coefficients for the remaining 11 step-lengths favor the RW benchmark. The AGS regression outcomes provide fairly strong evidence in favor of the LTF equation forecasts. For 22 
individual step-lengths, significantly better simulation accuracy is reported for the LTF forecasts. Once again, evidence of this is provided by the combination of a significantly positive slope coefficient along with positive LTF and RW error means. For the remaining individual steplengths, the AGS test favors the RW benchmark at the 12 month-ahead forecast and is statistically inconclusive at the final step-length. The result of the DM t-test across all step lengths is inconclusive.

Table 10. Paso del Norte Northbound Pedestrians Forecast Accuracy Rankings

\begin{tabular}{lllll}
$\begin{array}{l}\text { Step } \\
\text { Length }\end{array}$ & $\begin{array}{l}\text { Number of } \\
\text { Observations }\end{array}$ & U-statistic & $\begin{array}{l}\text { AGS Error } \\
\text { Differential }\end{array}$ & $\begin{array}{c}\text { DM RMSE } \\
\text { Differential }\end{array}$ \\
\hline 1-Month & 48 & LTF & LTF & Inconclusive \\
2-Months & 47 & LTF & LTF & \\
3-Months & 46 & LTF & LTF & \\
4-Months & 45 & LTF & LTF & \\
5-Months & 44 & LTF & LTF & \\
6-Months & 43 & LTF & LTF & \\
7-Months & 42 & LTF & LTF & \\
8-Months & 41 & LTF & LTF & \\
9-Months & 40 & LTF & LTF & \\
10-Months & 39 & LTF & LTF & \\
11-Months & 38 & LTF & LTF & \\
12-Months & 37 & RW & RW & \\
13-Months & 36 & LTF & LTF & \\
14-Months & 35 & LTF & LTF & \\
15-Months & 34 & RW & LTF & \\
16-Months & 33 & RW & LTF & \\
17-Months & 32 & RW & LTF & \\
18-Months & 31 & RW & LTF & \\
19-Months & 30 & RW & LTF & \\
20-Months & 29 & RW & LTF & \\
21-Months & 28 & RW & LTF & LTF \\
22-Months & 27 & RW & LTF & \\
23-Months & 26 & RW & LTF & \\
24-Months & 25 & RW & Inconclusive &
\end{tabular}

Sample Period: January 2003 - December 2006.

LTF, autoregressive integrated moving average linear transfer function. 
RW, random walk.

RMSE, root mean square error.

AGS, error difference regression test.

DM, non-parametric RMSE difference t-test.

In summary, the Ysleta-Zaragoza international port of entry simulation accuracy rankings for northbound pedestrian traffic predictions are mixed. For cargo vehicle and passenger vehicle forecasts at the Ysleta-Zaragoza bridge, the empirical evidence suggests that the LTF model exhibits greater predictive accuracy than their respective RW counterparts. Out-of-sample simulation rankings for the two bridge traffic categories at the Paso del Norte bridge are similarly mixed. For light vehicles, the metrics point to different conclusions with respect to predictive superiority of either approach. In the case of Paso del Norte pedestrian traffic forecasts, the statistical evidence favors the LTF simulations at more step-lengths than it does for the corresponding RW benchmarks. Taken as a whole, the out-of-sample rolling forecast empirics provide substantial support for the LTF models at each bridge, even though those results are not unanimous.

\section{Conclusion}

Cross-border traffic over the international bridges that connect El Paso, Texas and Ciudad Juarez, Chihuahua has increased as a consequence of regional economic growth and demographic expansion. Recent research has examined southbound traffic trends across these arteries, but data constraints have previously prevented empirical analysis of the impacts of tolls on northbound international bridge crossings from Ciudad Juarez into El Paso. Northbound international traffic volumes are expected to grow as the regional economy on both sides of the 
borders expands. Given the potential for such growth, this study conducts an empirical analysis of several variables that affect Borderplex northbound international traffic.

Linear transfer function equations are estimated using monthly data on traffic volumes across two bridges where tolls are charged. Data are from January 1990 through December 2006. Results indicate that toll increases will somewhat reduce northbound traffic volumes. Business cycle fluctuations on either side of the border also impact all three categories of bridge traffic crossing into the United States from Mexico at these two ports of entry. As expected, exchange rate variations induce different reactions. Peso depreciation is negatively correlated with northbound pedestrian and automobile volumes, but positively associated with northbound cargo vehicle traffic.

Four of the five price elasticity estimates suggest that northbound international bridge traffic within the Borderplex reacts very little to changes in toll tariffs. That indicates that tolls provide a good potential source of revenue to finance future maintenance and enhancement efforts for these structures. Given the pressures facing fiscal authorities in Mexico, the evidence reported above indicates that tolls provide a useful means for insuring that international bridge capacity is maintained at adequate levels along the northern border. Whether such outcomes are unique to the El Paso and Ciudad Juarez Borderplex economy is unknown. Research of crossborder traffic flows between other metropolitan economies located along the border with Mexico would be helpful in this regard.

\section{References}


Ashley, R., C.W.J. Granger and R. Schmalensee. "Advertising and Aggregate Consumption: An Analysis of Causality.” Econometrica 48 (1980): 1149-1168.

Ashur, S., J. Weissman, S. Perez, and A.J. Weissman. "Traffic Simulation at International Ports of Entry." Transportation Research Record 1763 (2001): 48-56.

Asteriou, D., and S.G. Hall. Applied Econometrics, $2^{\text {nd }}$ Edition. New York, NY: Palgrave Macmillan, 2011.

Brownstone, D., A. Ghosh, T.F. Golob, C. Kazimi, and D. Van Amelsfort. "Drivers' Willingness-to-Pay to Reduce Travel Time: Evidence from the San Diego I-15 Congestion Pricing Project.” Transportation Research A 37 (2003): 373-387.

Cervero, R. "Transit Pricing Research - A Review and Synthesis." Transportation 17 (1990): 117-139.

Charemza, W.W., and D.F. Deadman. New Directions in Econometric Practice, $2^{\text {nd }}$ Edition. Cheltenham, UK: Edward Elgar, 1997.

De Leon, M., T.M. Fullerton, Jr., and B.W. Kelley. "Tolls, Exchange Rates, and Borderplex International Bridge Traffic.” International Journal of Transport Economics 36 (2009): 223259.

Diamandis, P.F., G.P. Kouretas, and P. Tzanetos. "Modelling the Choice of Mode and Estimation of the Value of Travel time Savings for the Case of Rion-Antirion Suspension Bridge in Greece.” Annals of Regional Science 31 (1997): 473-489.

Diebold, F.X. and R.S. Mariano. "Comparing Predictive Accuracy." Journal of Business and Economic Statistics 13 (1995): 253-265.

Flyvbjerg, B., M.K.S. Holm, and S.L. Buhl. "How (In) Accurate are Demand Forecasts? The Case of Transportation.” Journal of the American Planning Association 71 (2005): 131-146.

Ferrari, P. "Road Network Toll Pricing and Social Welfare." Transportation Research B, 36 (2002): 471-483.

Fullerton, T.M., Jr. "Currency Movements and International Border Crossings.” International Journal of Public Administration 23 (2000): 1113-1123.

Fullerton, T.M., Jr. "Specification of a Borderplex Econometric Forecasting Model." International Regional Science Review 24 (2001): 245-260.

Fullerton, T.M., Jr. "Bordeplex Bridge and Air Econometric Forecast Accuracy." Journal of Transportation \& Statistics 7 (2004): 7-21.

Fullerton, T.M., Jr., and M.P. Barraza de Anda. "Borderplex Population Modeling." Migraciones Internacionales 4 (Number 3, 2008): 91-104. 
Fullerton, T.M., Jr., and A.L. Molina, Jr. "Borderplex Economic Outlook: 2007-2009.” Business Report SR07-2. El Paso, TX: University of Texas at El Paso Border Region Modeling Project, 2007.

Fullerton, T.M., Jr., and R. Tinajero. "Cross Border Business Cargo Vehicle Flows." International Journal of Transport Economics 29 (2002): 201-213.

Graham, D.J., and S. Glaister. "Road Traffic Demand Elasticity Estimates: A Review." Transport Reviews 24 (2004): 261-274.

Hirschman, I., C. McKnight, J. Pucher, R.E. Paaswell, and J. Berechman. "Bridge and Tunnel Toll Elasticities in New York.” Transportation 22 (1995): 97-113.

Hoogendoorn, S.P., and P.H.L. Bovy. "Pedestrian Travel Behavior Modeling." Networks \& Spatial Economics 5 (2005): 193-216.

Kolb, R.A. and H.O. Stekler. "Are Economic Forecasts Significantly Better than Naïve Predictions? An Appropriate Test." International Journal of Forecasting 9 (1993): 117-120.

Lin, F.B., and M.W. Lin. "Modeling Traffic Delays at Northern New York Border Crossings." Journal of Transportation Engineering 127 (2001): 540-545.

Loo, B.P.Y. "Tunnel Traffic and Toll Elasticities in Hong Kong: Some Recent Evidence for International Comparisons." Environment and Planning A 35 (2003): 249-276.

Matas, A., and J.L. Raymond. "Demand Elasticity on Tolled Motorways." Journal of Transportation \& Statistics 6 (2003): 91-108.

Meese, R., and K. Rogoff. "Empirical Exchange Rate Models of the Seventies: Do They Fit Out of Sample?” Journal of International Economics 14 (1983): 3-24.

Minasian, J. "Indivisibility, Decreasing Cost, and Excess Capacity: The Bridge." Journal of Law \& Economics 22 (1979): 385-397.

Mrkaic, M., and R. Pezdir. "Estimating Price Elasticities of Demand for Highway Transport Using High Frequency Data.” International Journal of Transport Economics 35 (2008): 217230.

Olszewski, P., and L.T. Xie. "Modelling the Effects of Road Pricing on Traffic in Singapore." Transportation Research A 39 (2005): 755-772.

Oum, T.H., W.G. Waters, and J.S. Yong. "Concepts of Price Elasticities of Transport Demand and Recent Empirical Estimates - An Interpretative Survey." Journal of Transport Economics \& Policy 26 (1992): 139-154. 
Pindyck, R.S., and D. L. Rubinfeld. Econometric Models and Economic Forecasts, $4^{\text {th }}$ Edition. Boston, MA: Irwin McGraw-Hill, 1998.

Podgorski, K.V., and K.M. Kockelman. "Public Perceptions of Toll Roads: A Survey of the Texas Perspective." Transportation Research A 40 (2006): 888-902.

Villegas, H., P.L. Gurian, J.M. Heyman, A. Mata, R. Falcone, E. Ostapowicz, S. Wilrigs, M. Petragnani, and E. Eisele. "Trade-offs between Security and Inspection Capacity - Policy Options for Land Border Ports of Entry." Transportation Research Record 1942 (2006): 1622.

West, C.T. "Structural Regional Factors that Determine Absolute and Relative Accuracy of U.S. Regional Labor Market Forecasts." Journal of Agricultural \& Applied Economics 35 (Supplement, 2003): 121-35.

Wuestefeld, N.H., and E.J. Regan. "Impact of Rate Increases on Toll Facilities." Traffic Quarterly 35 (1981): 639-655. 